\title{
Developing the Local Supply Chain for the Contract of the Century
}

\section{BY IBRAHIM ISMAYILOV, SAMIR TAGHIYEV, OLGA GODUNOVA AND FARZIN MIRMOTAHARI}

\section{Background}

IN 1994 THE MULTINATIONAL energy company BP, together with a group of other oil companies, signed a production sharing agreement with the government of Azerbaijan to develop the country's oil and gas wealth. This agreement was officially called the Azeri-Chirag-Guneshli (ACG) oil development and Baku-Tblisi-Ceyhan (BTC) oil pipeline projects, but was
- widely referred to as the "Contract of the Century." It offered Azerbaijan, an independent country following the collapse of the Soviet Union in 1991, the opportunity to use its natural resources to improve the lives of its people and ameliorate widespread poverty. The International Finance Corporation (IFC) was one of the leading financiers of this project.

During the late 1980s and early 1990s, Azerbaijan had endured the collapse of the Soviet Union, economic disintegration, and a devastating war with neighboring Armenia. The scale of economic collapse was severe even by Soviet standards: In 1995 GDP was only 42 percent of its 1990 pre-independence level. Unemployment was endemic: out of a total popula-

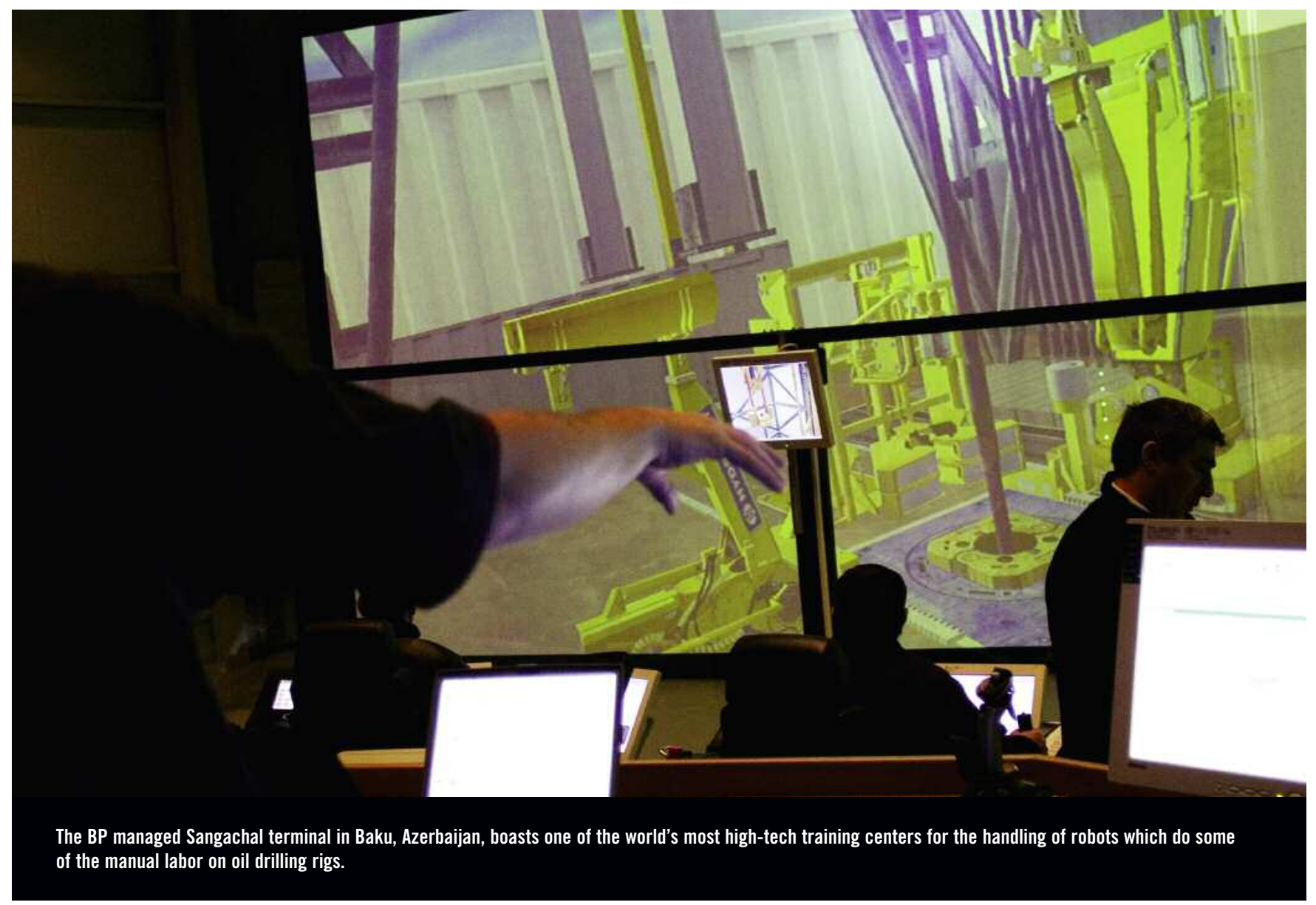


tion of 8 million, about one million Azerbaijanis were refugees and internally displaced persons who had fled the areas occupied by Armenian forces and another 2 million Azerbaijanis had left the country, mainly for Russia to find work.

All this could change with the "Contract of the Century." It could not only provide massive oil revenues for the Azerbaijani government, but also offer an opportunity for a large part of the Azerbaijani private sector to rebuild itself by working with BP and other major oil and gas service companies. But to do this Azerbaijani companies would have to compete with international firms for contracts which demanded international quality levels. For most local companies, this seemed an almost insurmountable obstacle.

\section{The Enterprise Centre}

TO ADDRESS THIS GRUCIAL ISSUE, in 2002 BP launched the Baku Enterprise Centre (EC) as a one-stop shop where local suppliers could obtain information, training and other forms of technical assistance, in order to bid for and win supply contracts with BP and other large companies in Azerbaijan. IFC, as the lead financier of the ACG-BTC Project hired a Small and Mediumsized Enterprise Linkages $\mathrm{Co}$-ordinator who was based in the EC in order to co-ordinate BP and IFG support for SMEs. Various types of training and mentoring services in technology, tenders and bidding, basic business disciplines and other fields were launched and continue to be provided at the EC.

The Centre also built a comprehensive supplier database to help link local firms with foreign companies in need of a vendor. To this day an electronic job board lets companies know in a timely, efficient way about potential opportunities. In addition, the EC sponsors a variety of fee-based courses to enhance general economic opportunities for entrepreneurs, and to improve the chances that small local businesses will win contracts on which they bid.

The EC also encourages international contractors to invest in training and infrastructure and to source materials and services locally, and provides a forum/collaboration facility for various NGOs, international financial institutions and development agencies that contribute to business development in Azerbaijan.

In another joint project between IFG and $\mathrm{BP}$, the Azerbaijan Bank Training Center (ABTC) was contracted to deliver small business courses in local languages using a feebased system. The goal was to build up the local small business services sector, create a market for such services, and improve the skills of the local consultants providing them. Post-project, ABTC continues to provide training and consulting services to local companies in Azerbaijan in a commercially sustainable way.

In June 2007 , BP and its co-venturers in the oil and gas projects in Azerbaijan also launched the Enterprise Development and Training Program (EDTP)-a new threeyear multi-million initiative in support of local business development. The program is part of BP's efforts to continue to increase the local content share of their total contracts in Azerbaijan, and is financed through the oil and gas co-ventur- ers Regional Development Initiative and coordinated by the Enterprise Center.

\section{The need for access to finance}

DESPITE THE SUCCESS OF BP'S local enterprise development efforts, it became apparent early on that the technical and business support and training were insufficient by themselves. Without access to affordable finance, local enterprises would find it very difficult to compete with international companies for the contracts offered by the BP's oil and gas projects. Most local SME suppliers required new technology and equipment to achieve the quality of service required by BP. Financing from local banks was not available, as they required collateral equal to 100 percent- 150 percent of the loan amount and the terms were inflexible.

BP and IFC began to consider a proposal to develop the financing to improve access to finance for local SME suppliers. Out of these discussions came the concept of the Supplier Finance Facility (SFF) pilot project, to be developed jointly by IFC and BP, and implemented through a local bank in Azerbaijan. The parties agreed to start a pilot project with the objective to test the viability of supplier finance, to gain experience and identify key lessons.

In June 2006, IFC and BP launched a $\$ 316,000$ pilot Supplier Finance Facility (SFF) involving the Microfinance Bank of Azerbaijan, providing medium-term funding for working capital and capital expenditures to small and medium oil services suppliers to BP and its partners in Azerbaijan. Suppliers were able to use their contracts with BP as collateral, thereby reducing the need for using fixed assets and cash (which in many cases were not available). In late 2006, the pilot was expanded to a $\$ 15$ million investment project involving the three parties. So far, applications from eight suppliers in a number of industry sectors have been evaluated - from transportation services to printing, engineering and waste management. Two applications have been approved and a substantial increase in credit applications and disbursements is expected in 2008 , according to IFC estimates.

\section{Positive results to date}

IN 2007, BP and its co-venturers spent approximately $\$ 111$ million on procurement from local SMEs, increasing dramatically from a baseline of $\$ 13$ million in 2002. During 2006 the company worked with 393 SMEs. From 2003-2006, 1606 new business contracts, worth \$24,9 million, were awarded to local SMEs. During this same period, $5^{62}$ SMEs received training on the contract tendering process, quality control, and health, safety and environment (HSE) standards.

\section{Case study: Debet}

AN EXAMPLE OF A LOGAL GOMPANY which benefited from the EC and SFF was Debet. Founded in 1997, the company manufactures and supplies quality safety gloves, helmets, work wear, corporate clothing and promotional wear for BP 


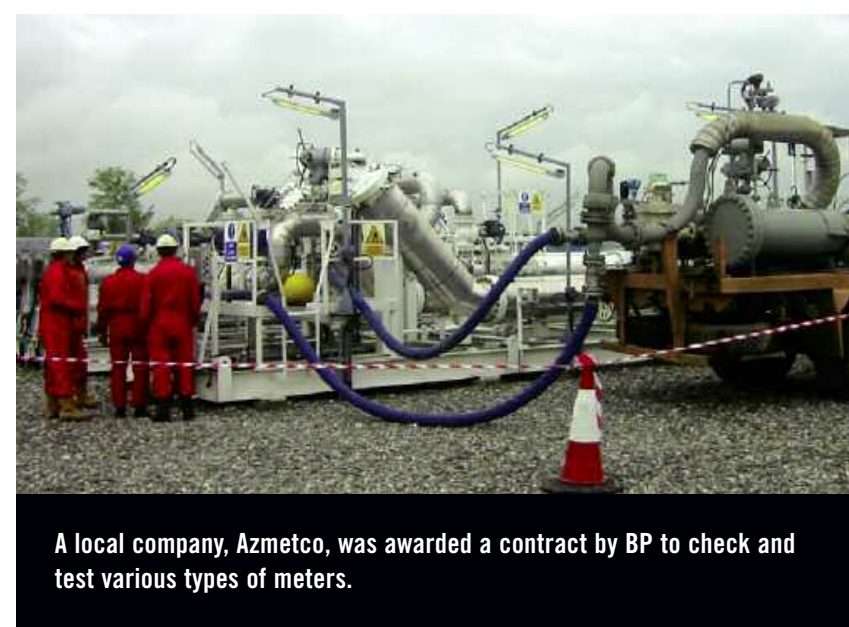

and numerous other companies in Azerbaijan. Currently Debet Uniform employs 117 people.

The development of Debet Uniform was possible through the supplier development project launched in 2004 and implemented in partnership with German Technical Cooperation (GTZ), the Enterprise Centre, and IFC. GTZ was contracted specifically to provide an experienced specialist-a mentor-that could provide the technical and business training and advisory services that were needed. A gap analysis of Debet was conducted which showed where the key areas that needed improvement were. Since 2006 this project has been funded by BP's Regional Development Initiative (RDI), a long term socio-economic development program funded by BP and its co-venturers in major oil and gas projects in Azerbaijan.

In 2007, BP awarded a \$6 million, 3-year contract to Debet Uniform Ltd for the supply of personal protective equipment in Azerbaijan and Georgia. A key condition for Debet to be able to fulfil this contract was to obtain medium/long-term financing. Debet Uniform received a loan from the Suppliers Finance Facility, using its contract with BP as collateral, and with a term of 3 years, equal to the term of the BP supply contract. Debet's work, which was previously performed by a foreign firm, was an example and signal to the market place that with proper support and assistance, local companies could compete and win in the international market place!

Due to rapidly increasing oil exports and the high oil price, Azerbaijan's economy grew at an amazing rate of 34 percent in 2007. BP and IFC's assistance will help ensure than small businesses can also participate, develop and benefit from this growth.

Ibrahim Ismayilov is BP Manager of the Regional Development Initiative (RDI) in Azerbaijan.

Samir Taghiyev is BP Manager of the Enterprise Centre in Azerbaijan. Olga Godunova is Operations Officer of PEP-CEU in Baku, Azerbaijan. Farzin Mirmotahari is Operations Officer of the Global Linkages Unit for Azerbaijan at the International Finance Corporation.
The Next 4 Billion

continued from page 9

income data are buttressed by detailed, standardized expenditure data in a substantial subset of countries.

\section{A new way of thinking about poverty reduction}

THE BOP MARKET ANALYSIS in this study is intended to help businesses and governments think more creatively about new products and services that meet BoP needs and about opportunities for market-based solutions to achieve them. For businesses, characterizing the market in empirical terms is an important first step toward identifying business opportunities, considering business models, developing products, and expanding investment in BoP markets. Put simply, while an analysis of the depth of poverty does not generate private sector enthusiasm for investment, an analysis of BoP market size and willingness to pay might-and is thus a critical step toward market-based solutions. For governments, such an analysis can help focus attention on reforms needed in the operating and regulatory environment to allow a larger role for the private sector.

The market-based approach to poverty reduction and empirical market data described in this report are equally important for the development community. They can help frame the debate on poverty reduction more in terms of enabling opportunity and less in terms of aid. A successful market-based approach would bring significant new private sector resources into play, allowing development assistance to be more sharply targeted to the segments and sectors for which no viable market solutions can presently be found. Market-based approaches and smart development policies are synergistic strategies.

Perhaps most important, a market-oriented approach recognizes that only sustainable solutions can scale to meet the needs of 4 billion people.

Allen L. Hammond is Vice President for Innovation and Special Projects at the World Resources Institute.

The Next Four Billion: Market Size and Business Strategy at the Base of the Pyramid is an International Finance Corporation/ World Resources Institute joint publication. Visit www.nextbillion.net.

\section{Endnotes}

1 In this study, current U.S. dollars means 2005 dollars. Unless otherwise noted, however, market information is given in 2005 international dollars (adjusted for purchasing power parity); for convenience, BoP and mid-market income cutoffs are given in international dollars for 2002 (the base year to which household surveys used in the analysis for the report have been normalized). U.S. dollars are generally denoted by US $\$$, international dollars by $\$$.

2 World Resources Institute, World Bank, United Nations Development Programme, and United Nations Environment Programme, World Resources Report: The Wealth of the Poor, 2005, Washington DC.

3 International Labour Organisation, Key Indicators of the Labour Market, 2nd ed., 2002. Geneva: ILO.

4 Frederich Schneider, "Size and Measurement of the Informal Economy in 110 Countries around the World" Working Paper 2005-13, Center for Research in Economics, Management and the Arts, Johannes Kepler University of Linz. 